\title{
Removal of Uranium-238 Ions from Contaminated Ground Water Containing NORM by Adsorption on Fly Ash Carbon: Equilibrium, Kinetic and Thermodynamic Studies
}

\author{
E.M.Abdel Rahman*1, S.S.M.Hassan ${ }^{2}$, G.M.El-Subruiti' ${ }^{3}$, A.H.Kamel ${ }^{2}$, H.M.Diab ${ }^{4}$ \\ (1) Central lab, Nuclear and Radiological Regulatory Authority, Cairo, Egypt \\ ${ }^{(2)}$ Chemistry Department, Faculty of Science, Ain Shams University, Cairo, Egypt \\ (3) Chemistry Department, Faculty of Science, Alexandria University, Alexandria, Egypt \\ (4) Radiation Protection Department, Nuclear and Radiological Regulatory Authority, Cairo, Egypt
}

\begin{tabular}{|c|c|}
\hline ARTICLE INFO & ABSTRACT \\
\hline Article history: & Water purification from radionuclides was investigated using an effective and low- \\
\hline Received: $14^{\text {th }}$ Sep 2020 & cost adsorbent produced in high quantities from the fuel combustion in power stations \\
\hline Accepted: $20^{\text {th }}$ Oct 2020 & where mazote, coal and other fuels are extensively used. Fly ash's particles were used to \\
\hline Keywords: & investigate the removal of uranium-238 ions, in the concentration range of $27.9,55.8$, \\
\hline Fly ash carbon, & 111.6 $\mathrm{Bq} / \mathrm{l}$ from ground water. In order to investigate the effect of various parameters \\
\hline $\begin{array}{l}\text { Kinetic and Thermodynamic } \\
\text { adsorption, NORM, }\end{array}$ & $\begin{array}{l}\text { including } \mathrm{pH} \text {, contact time, initial metal ion concentration, dose adsorbent and } \\
\text { temperatures, batch tests have been performed. The optimum contact time was } 30\end{array}$ \\
\hline Uranium-238, & minutes and the appropriate $\mathrm{pH}$ was found to be 4.5 . The temperature effects on kinetics \\
\hline $\begin{array}{l}\text { Scanning electron } \\
\text { microscopy. }\end{array}$ & $\begin{array}{l}\text { and equilibrium were closely investigated in fly ash pores. Endothermic findings and a } \\
\text { temperature rise resulted in an increase in the adsorption rate of uranium-238. Data was } \\
\text { applied at different temperatures }(293,303 \text { and } 313 \mathrm{~K}) \text { with the isotherms Langmuir, } \\
\text { Freundlich and Dubinin - Radushkevich. The best way to explain the data was to find the } \\
\text { Langmuir Adsorption Model. Adsorption kinetics have been studied in pseudo-first, } \\
\text { pseudo-second order. A pseudo-second-order mechanism was the best in fitting the data. } \\
\text { Thermodynamic parameters; } \Delta \mathrm{H}^{\circ}, \Delta \mathrm{G}^{\circ} \text {, and } \Delta \mathrm{S}^{\circ} \text { have been studied. SEM is used to } \\
\text { assess morphological changes in the fly ash surfaces following adsorption of uranium-238 } \\
\text { ions. }\end{array}$ \\
\hline
\end{tabular}

\section{INTRODUCTION}

When drilling oil wells and ground water wells, ground water comes out contaminated with naturally occurring radioactive materials (NORM) such as uranium, thorium, potassium and radium. The contamination of water resources by natural radioactive isotopes results from different concentrations of the radioactive metal ions and this has caused a global concern. Most of these radioactive metals have toxic and carcinogenic properties, and they seriously threaten human health and the aquatic environment when they enter the water and food chain. Consequently, recent studies have focused mainly on the exploration of new absorbers having a high absorption rate, high adsorption capacity, and high selectivity for adsorption of hazardous and radioactive metal ions [1]. Uranium is a radioactive metal that occurs in nature and is widespread in the crust of the earth. It is concentrated in certain layers of the soil. Uranium is a cancerous agent and a renal poison that has a harmful effect on the human body. Therefore, when injecting radioactive metal ions into this groundwater and before entering into the atmosphere, these radioactive metal ions must be eliminated since harmful radioactive metal ions can be introduced into the food chain through groundwater. Also, water is important for all biological and industrial processes, and any change in the characteristics of water will harm the environmental balance [2]. In this study, fly ash is used as an effective adsorbent to remove radionuclides from water rather than considering it as an industrial useless absorber . 


\section{EXPERIMENTAL}

\subsection{Chemicals}

A stock sample of water collected from crude oil companies in Sueze governorate contains NORM. Fly ash, collected from power stations (El-Zawia power station), was used. Hydrochloric acid and sodium hydroxide were used in adjusting the $\mathrm{pH}$ of the solutions.

\subsection{Measurement and analysis}

Dragon Digital magnetic stirrer MS-H-Pro with PT 1000 sensor; IKA ® KS4000i control were used in the tests. The sensors were also used. Samples $(100 \mathrm{ml})$ of underground water containing NORM were withdrawn in the storage tank. The HPGe detector was used for validation of the concentration stocks using the gammaray spectrometer. An HI2211 Ph/ORP meter HANNA instruments $\mathrm{pH}$-meter was used to adjust the $\mathrm{pH}$ of the solutions.

\subsection{Procedure}

The batch techniques used due to the small size of fly ash. Therefore, it has not affected the batch sample taking at time intervals. These experiments were performed by stirring fly ash and a $100 \mathrm{ml}$ of underground water containing uranium-238 as NORM. Different $\mathrm{pH}$ values of the solution ranged from 2-9 were studied to each solution to get the optimum $\mathrm{pH}$ for solution. The $\mathrm{pH}$ was adjusted using hydrochloric acid and sodium hydroxide. Experiments were carried out at different temperatures 293,303 and $313 \mathrm{~K}$, and contact times: 10,20 and $30 \mathrm{~min}$, the initial concentrations of uranium-238 were $27.9,55.8,111.6 \mathrm{~Bq} / \mathrm{l}$ and fly ash dosage. A $100 \mathrm{ml}$ of the aliquots were taken from the reaction solution at different time intervals for analysis [3]. The samples were taken at regular time intervals. Then, they were analyzed using the gamma-ray spectrometer based on high purity germanium (HPGe) detector. The solution was filtered to separate the precipitate materials from the solution. Fly ash carbon before and after adsorption of uranium-238 ions, was tested by the gamma-ray spectrometer based on high purity germanium (HPGe) detector techniques. The results were used to estimate the equilibrium adsorption capacity $\mathrm{q}_{\mathrm{e}}(\mathrm{mg} / \mathrm{g})$ as the difference between the initial and final equilibrium $\mathrm{q}_{\mathrm{t}}(\mathrm{mg} / \mathrm{g})$ of the metal concertation and as the difference between the initial and time changes ( $t$ ) of the metal concentration [4]:

$$
\mathrm{q}_{\mathrm{e}}=\frac{(\mathrm{Co}-\mathrm{Ce}) \mathrm{V}}{\mathrm{m}}
$$

$$
\mathrm{q}_{\mathrm{t}}=\frac{(\mathrm{Co}-\mathrm{Ct}) \mathrm{V}}{\mathrm{m}}
$$

Also, the change in the $\%$ removal with time was determined from this equation:

$$
\% \text { Removal }=\frac{\mathrm{Co}-\mathrm{Ct}}{\mathrm{Co}} \times 100
$$

Where $\mathrm{C}_{\mathrm{o}}(\mathrm{mg} / \mathrm{l})$ is the solution of the initial metal ion concentration, $C_{e}(\mathrm{mg} / \mathrm{l})$ is the final concentration of metal ions. $\mathrm{C}_{\mathrm{t}}(\mathrm{mg} / \mathrm{l})$ is the concentration of metal ions in the solution after time $(t), m$ is the weight of the fly ash used $(\mathrm{g})$ and $\mathrm{V}$ is the volume of the solution (l).

\section{RESULTS AND DISCUSSION}

\subsection{Factors affecting the reaction rate}

\subsubsection{Effect of $\mathbf{p H}$}

$\mathrm{pH}$ is an essential factor that causes aqueous solution cation elimination. The dependence on $\mathrm{pH}$ is linked to both the solution's metal chemistry and the ionizing conditions of the working sorbent groups which influence the availability of binding locations. [5]. To determine this parameter's effect on cation adsorption, equilibrium studies were carried out in the $\mathrm{pH}$ range from 2.0 to 9.0. By adding the appropriate amount of dilute $\mathrm{NaOH}$ or $\mathrm{HCl}$ solution the $\mathrm{pH}$ of the metal ions solution was changed to different values. The initial concentration of uranium-238 was $111.6 \mathrm{~Bq} / \mathrm{l}$ and the contact time for adsorption was kept at $30 \mathrm{~min}$ to confirm the complete equilibrium [6].

Figure (1) shows the effect of the initial $\mathrm{pH}$ on the adsorption process indicating that the adsorbed amount of uranium-238 ions increases with increasing $\mathrm{pH}$, and the maximum adsorption potential for uranium-238 is obtained at $\mathrm{pH} 4.5$ due to the negative fly ash surface charge at high $\mathrm{pH}$ values. However Figure (2) shows that the efficiency of removal of uranium-238 improved by increasing the $\mathrm{pH}$ from 2.0 to 4.5 . A poor adsorption occurs in a heavy acid medium, but a higher $\mathrm{pH} 4.5$ can be seen leading to a higher metal absorption [7]. Acid conditions are not favorable since most of the component functional groups are protonated leaving few ionized groups available. This may explain the slow adsorption in the acid medium due to rivalry between protons and metal species. The highest $\mathrm{pH}$ absorption value can be due to the presence of a free lone pair of electrons on deprotonated oxygen atoms, which are ideal for coordination with metal ions [8]. 


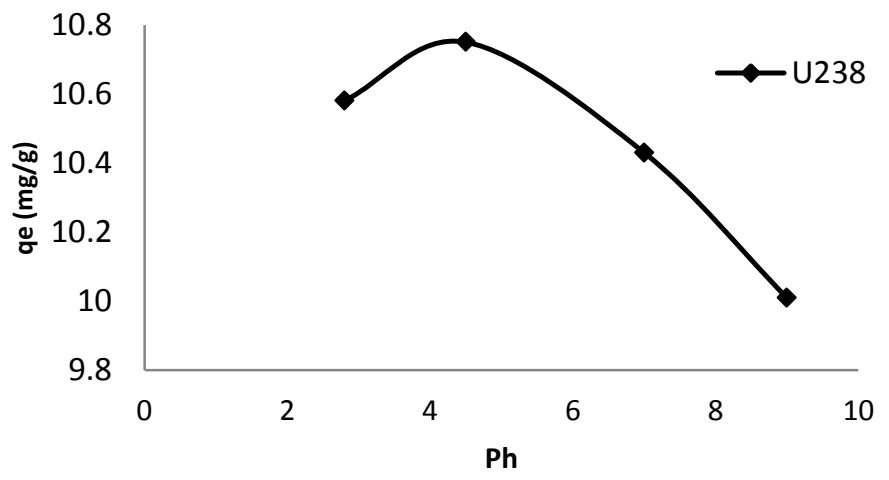

Fig. (1): A relation between $\mathrm{q}_{\mathrm{e}}$ and $\mathrm{pH}$ for the adsorption of uranium-238 onto fly ash carbon (The initial concentration $=100 \mathrm{mg} / \mathrm{l}$, fly ash carbon dose $=1.0 \mathrm{~g}$, shaking speed $=600 \mathrm{rpm}, \mathrm{T}=303 \mathrm{~K}$ and time $=30$ min).

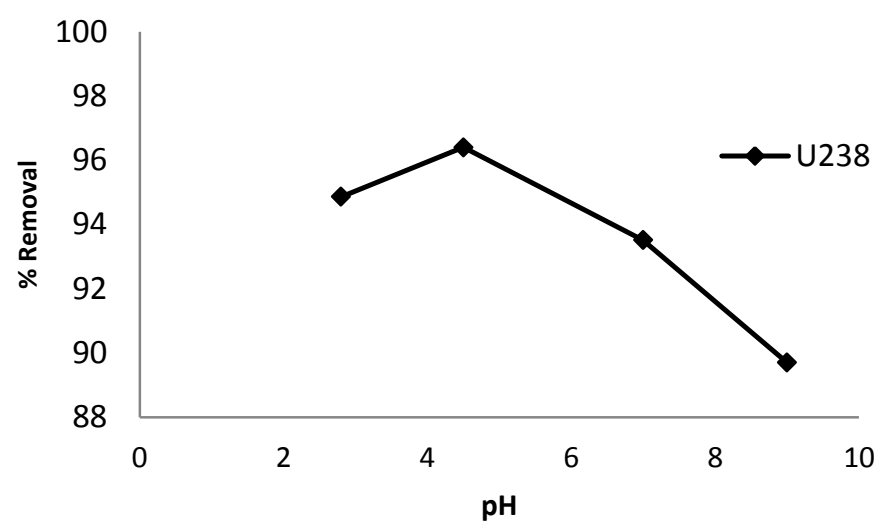

Fig. (2): Effect of pH for on adsorption of uranium-238 onto fly ash carbon (The initial concentration $=111.6 \mathrm{~Bq} / \mathrm{l}$, fly ash carbon dose $=1.0 \mathrm{~g}$, stirring speed $=600 \mathrm{rpm}$, $\mathrm{T}=293 \mathrm{~K}$ and time $=\mathbf{3 0} \mathrm{min}$ )

\subsubsection{Effect of contact time}

The use of fly ash adsorbents of the metal ions measured is used to evaluate potential relation and removal operation, and to guarantee an adequate time to remove the target metal ions entirely. In 30 minutes, metal ions were measured and the concentration was determined for each sample. Results have been reported and the time profile of uranium-238 ion adsorption has been traced. The adsorbent separated the metal ions from the solution after $30 \mathrm{~min}$ [9]. The optimal touch time for uranium -238 adsorption was therefore deemed to be 30 minutes. Figure.(4)shows the removal of metal ions with contact time. three different initial concentrations (27.9, $55.8,111.6 \mathrm{~Bq} / \mathrm{l})$ on $1.0 \mathrm{~g} / \mathrm{l}$ of fly ash carbon were used. The adsorption efficiency was determined based on the difference in metal concentration in the aqueous solution before and after equilibrium adsorption had been reached. Over time the release of metal ions increases and reaches a limit of 30 minutes. It is evident that metal ion removal can be obtained in two stages: one in which the removal rate is very high [10].
A large number of sites was then eventually reached for sorption activity and adsorption equilibrium. Figure(3) presents a plot of adsorbed uranium metal ion $(\mathrm{mg} / \mathrm{g}$ ) as opposed to the touch time ( $\mathrm{min}$ ) for various initial metal ion concentrations $(27.9,55.8,111.6 \mathrm{~Bq} / \mathrm{l})$ [11].

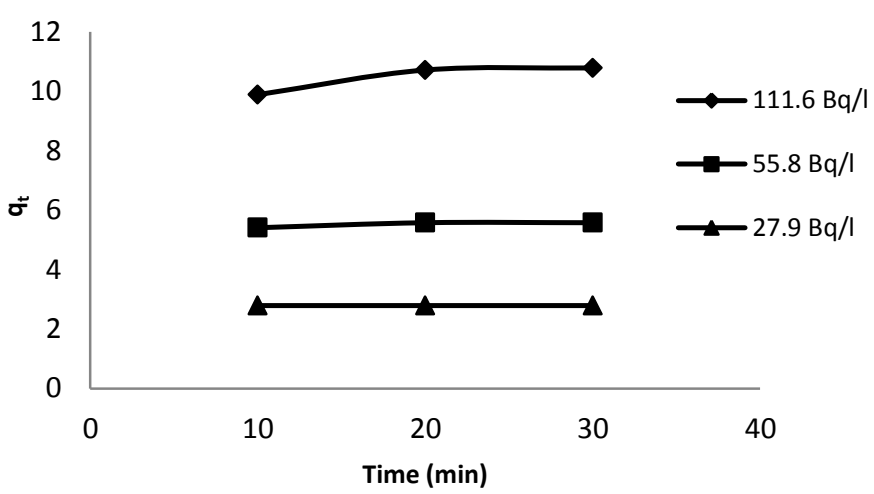

Fig. (3): The relationship between $\mathrm{q}_{\mathrm{t}}(\mathrm{mg} / \mathrm{g})$ and time at a different concentration of uranium ions on fly ash carbon at $600 \mathrm{rpm}, 293 \mathrm{k}$ and $1.0 \mathrm{~g}$ of fly ash carbon

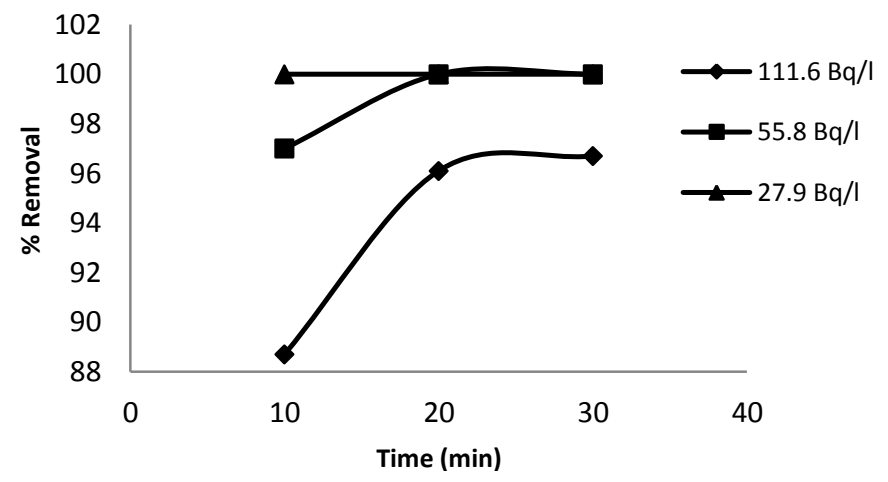

Fig. (4): Effect of contact time for adsorption of uranium ions onto fly ash carbon (the initial concentration $=111.6$, 55.8, 27.9 Bq/l, fly ash carbon dose $=1.0 \mathrm{~g} / \mathrm{l}, \mathrm{pH}=4.5$, stirring speed $=600 \mathrm{rpm}$, contact time $=30 \mathrm{~min}$ and $\mathbf{T}=293 \mathrm{~K})$.

\subsubsection{Effect of the dose adsorbent}

Adsorbent dosage is a major parameter, because the adsorbent has the potential for the initial adsorbent concentration. The adsorption dependency of cations uranium-238 on fly ash carbon under a specified range of operating conditions was studied by varying its quantity from $0.5,1.0,2.0 \mathrm{~g} / 1$. Other parameters $(\mathrm{pH}$, agitation rate, temperature, initial concentration and contact time) are preserved. [12]. Figure (6) shows that the amount of uranium-238 ion reduction rose from $88.1 \%$ to $100 \%$ by using fly ash carbon as the dose of adsorption as it rose from 0.5,1.0, $2.0 \mathrm{~g} / 1$. Figure(5). It has been found that the volume of the adsorbed uranium -238 ions decreases with increasing in the dose of adsorbate at constant initial concentration [13]. 


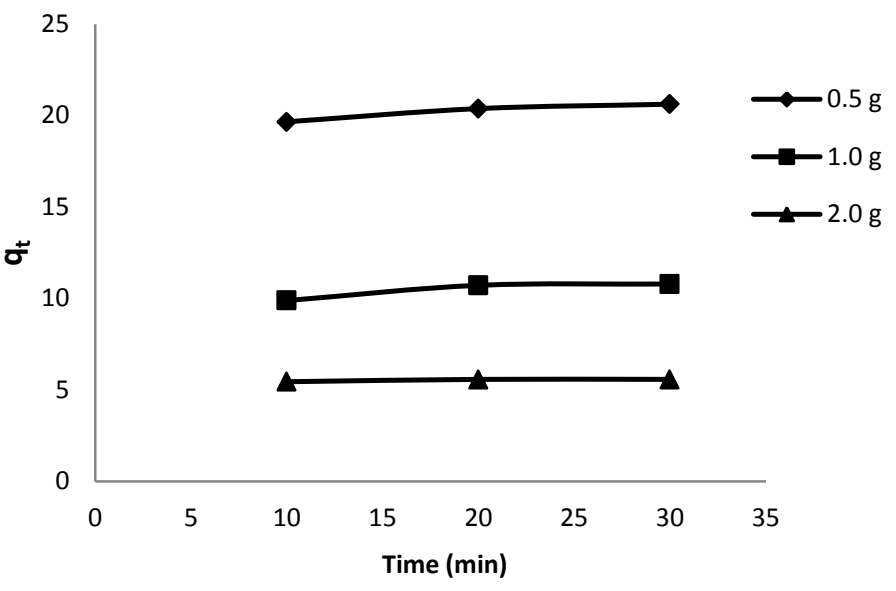

Fig. (5): The relation between $\mathrm{q}_{\mathrm{t}}$ and time at different doses of fly ash carbon at $600 \mathrm{rpm}, 293 \mathrm{~K}$ and initial concentration of $111.6 \mathrm{~Bq} / \mathrm{l}$ of uranium-238 ions

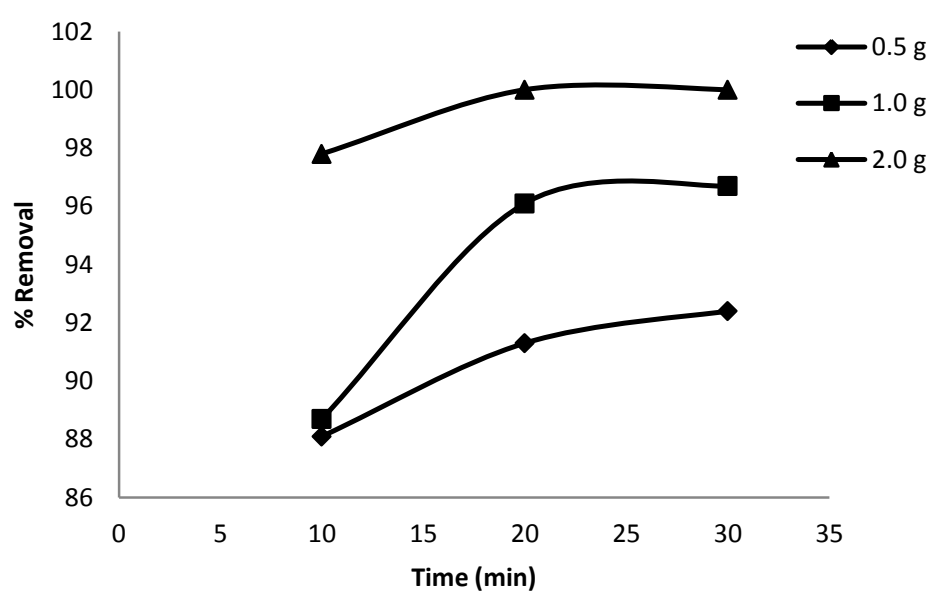

Fig (6): The relation between \% removal and time at different doses of fly ash carbon at $600 \mathrm{rpm}, 293 \mathrm{~K}$ and initial concentration of $111.6 \mathrm{~Bq} / \mathrm{l}$ of uranium-238 ions

\subsubsection{Effect of initial uranium-238 ions concentration}

The adsorption of metal ions was greatly affected by the original concentration of metal ions in aqueous solutions. The percentage of uranium-238 removal decreased from 100 percent to 96.7 percent, with initial ion concentrations rising from 27.9, 55.9 to $111.6 \mathrm{~Bq} / 1$. The ratio of the original uranium- 238 concentration to the available adsorption sites was low at the low metal ions concentration, and therefore a complete adsorption took place. At higher metal ion levels, however, the adsorption locations available were decreased by the level of uranium-238 in the solution, because there were not enough active sites on fly ash carbon, and thus, the percentage sorption of metal decreased. The sum of metal ions, $\mathrm{q}_{\mathrm{e}}(\mathrm{mg} / \mathrm{g})$, increased with increasing the initial concentration as seen in Figure (7). [14].

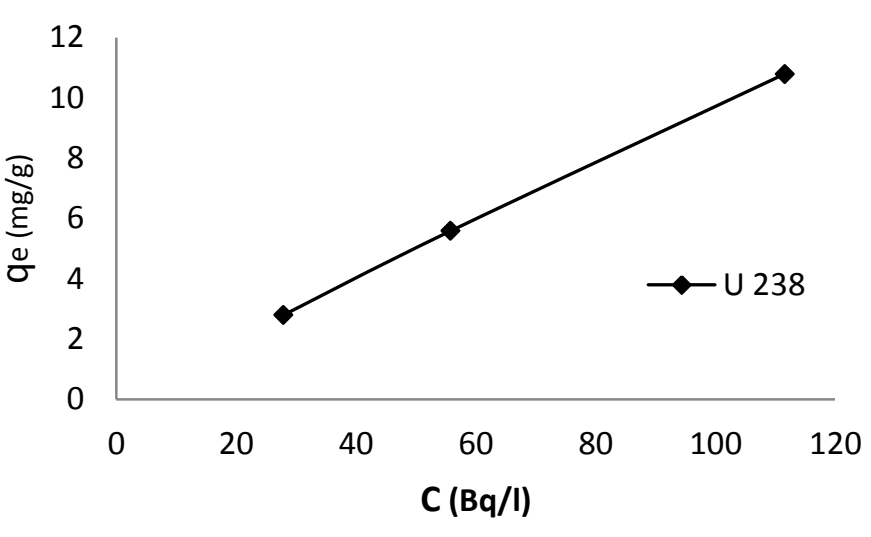

Fig. (7): The relation between $q_{e}$ and initial concentration for uranium-238.

\subsubsection{The effect of temperatures}

Temperature plays a crucial role in the adsorption process because increasing the temperature reduces the viscosity of the solution, which in turn raises the rate of diffusion of adsorbate molecules over the surface boundary layer of the adsorbent which resulting in higher adsorption [15]. Temperature shifts can affect the equilibrium of the adsorbent ability. Unit adsorption tests were conducted at various temperatures of $293 \mathrm{~K}$, $303 \mathrm{~K}$ and $313 \mathrm{~K}$. The effect of temperature on the adsorption capacity of fly ash carbon was studied at constant initial concentration of $111.6 \mathrm{~Bq} / \mathrm{l}$ and $600 \mathrm{rpm}$ for the uranium-238 ions, optimum $\mathrm{pH}$ values of 4.5 for uranium ion $1.0 \mathrm{~g} / \mathrm{l}$ of fly ash carbon. It is clear from Figure (8) that the degrees of adsorption increase as the temperature rises and the extreme adsorption exceeds $313 \mathrm{~K}$. A higher temperature implies improved uranium238 ions mobility and reduction of retardants acting on diffuse ions, which improves the sorbent capacities, improves the chemical interaction between adsorbent and the formation of active surface centers [16]. This rise suggests an endothermic mechanism for adsorption [17]. The adsorption temperature sensitivity is related to changes in different thermodynamic parameters. For determining the essential thermodynamic properties other than normal Gibbs free energy the adsorption balance data obtained at different temperatures have been used $\left(\Delta \mathrm{G}^{\circ}\right)$, standard enthalpy change $\left(\Delta \mathrm{H}^{0}\right)$ and standard entropy change $\left(\Delta \mathrm{S}^{\mathrm{o}}\right)$. The following equations have been used to estimate these parameters:

$$
\begin{aligned}
& K_{e}=\frac{q_{e}}{C_{e}} \\
& \Delta G^{o}=-R T \ln K_{e} \\
& \Delta G^{o}=\Delta H^{o}-T \Delta S^{o}
\end{aligned}
$$


$\ln K_{e}=\frac{\Delta S^{o}}{R}-\frac{\Delta H^{o}}{R T}$

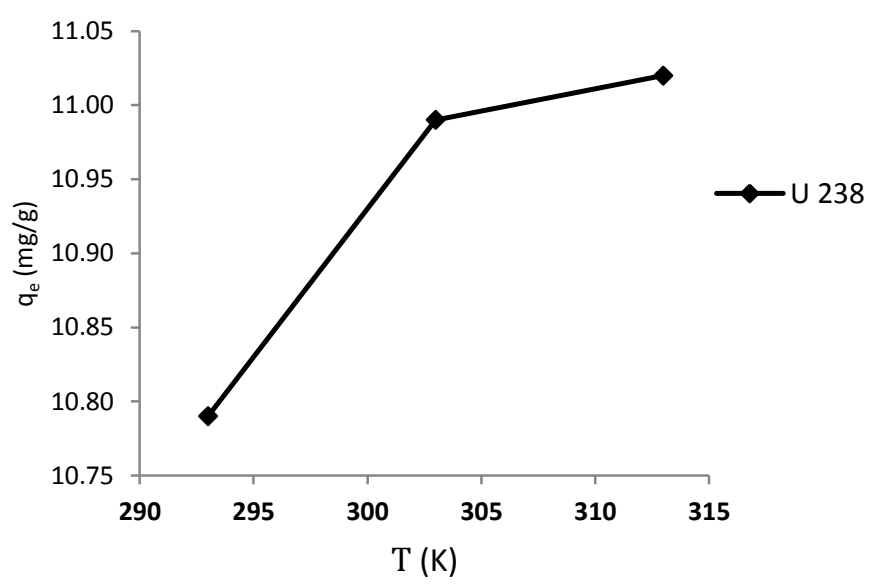

Fig. (8): The relation between $\mathrm{q}_{\mathrm{e}}$ and temperature at a constant initial concentration of $111.6 \mathrm{~Bq} / \mathrm{l}, 1.0 \mathrm{~g} / \mathrm{l}$ dose of fly ash carbon and $600 \mathrm{rpm}$

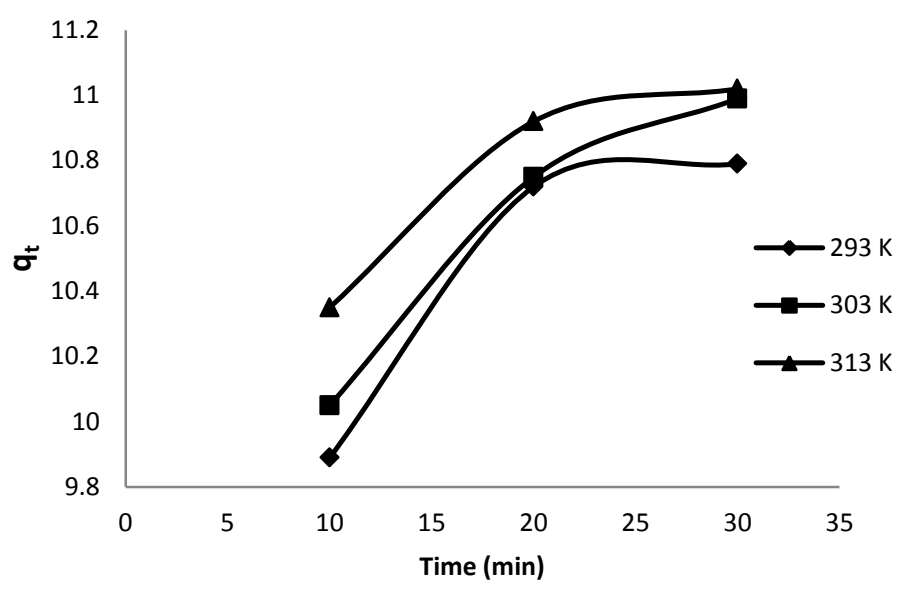

Fig. (9): The relationship between $q \mathrm{t}$ and time at different temperature, a constant initial concentration of 111.6 $\mathrm{Bq} / \mathrm{l}, 1.0 \mathrm{~g} / \mathrm{l}$ dose of fly ash carbon and $600 \mathrm{rpm}$ for uranium-238

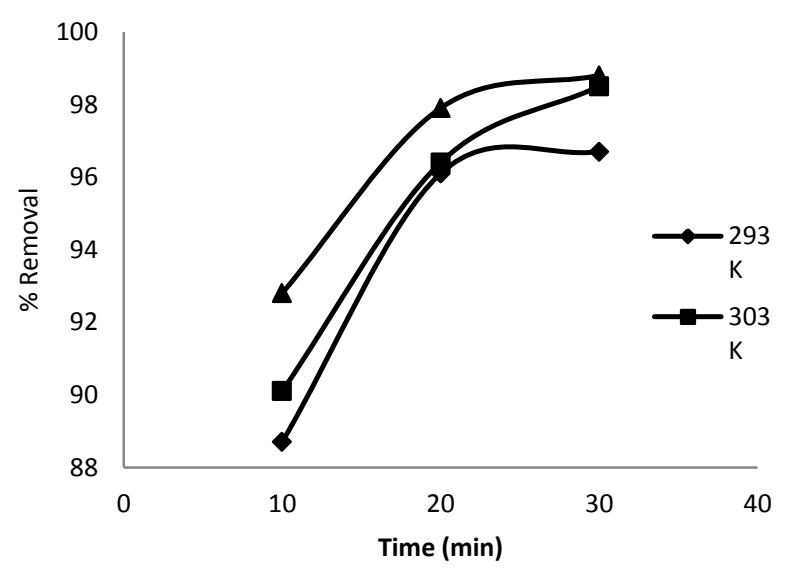

Fig. (10): The relationship between $\%$ removal and time at different temperature, a constant initial concentration of $111.6 \mathrm{~Bq} / \mathrm{l}, 1.0 \mathrm{~g} / \mathrm{l}$ dose of fly ash carbon and $600 \mathrm{rpm}$ for uranium-238
Where $\mathrm{q}_{\mathrm{e}}(\mathrm{mg} / \mathrm{g})$ is the sum of uranium-238 ions adsorbed on the fly ash material from the equilibrium solution, $\mathrm{C}_{\mathrm{e}}(\mathrm{mg} / \mathrm{l})$ is the concentration of uranium-238 ions in the solution, $\mathrm{R}(\mathrm{J} / \mathrm{mol} . \mathrm{K})$ is the gas constant $8.314, \mathrm{~T}(\mathrm{~K})$ is the absolute temperature, and $\mathrm{K}_{\mathrm{e}}(\mathrm{l} / \mathrm{g})$ is the adsorption equilibrium constant. $\Delta \mathrm{H}^{\mathrm{o}}$ and $\Delta \mathrm{S}^{\mathrm{o}}$ were obtained from the slope and intercept of the van't Hoff plot of $\ln \left(\mathrm{K}_{\mathrm{e}}\right)$ versus $1 / \mathrm{T}$ as seen in Figure (11) and the values of $\Delta \mathrm{G}^{\mathrm{o}}, \Delta \mathrm{H}^{\mathrm{o}}$ and $\Delta \mathrm{S}^{\mathrm{o}}$ were listed in Table (1). From the values reported in this experiment, it could be observed that the Gibbs free uranium-238 adsorption energy on fly ash carbon decreased with increasing temperature and was negative at all temperatures measured. In other words, the adsorption process requires temperature. The negative value of $\Delta \mathrm{H}^{\mathrm{o}}$ shows that the adsorption procedure is exothermic in nature and the negative Gibbs' free energy $\left(\Delta G^{\circ}\right)$ values confirm that the adsorption process of uranium-238 ions requires the temperature to rise. Due to the high adsorption rate and the equilibrium time range, the metal ions are readily adsorbed at high temperature [18]. The positive $\Delta \mathrm{S}^{\mathrm{o}}$ evidence indicates the improved randomness of the solid / liquid interface during the adsorption of uranium-238 ions, thereby allowing randomness in the device [19]. Figure (9) shows that the amount of adsorbed uranium238 ions grows as the temperature rises. The increase in the adsorption of uranium-238 ions with temperature may be due to the increased mobility of ions, which in turn increases the number of ions that interacted on the adsorbent surfaces with active sites. [20].The decrease in the value of $\Delta \mathrm{G}^{\circ}$ with the increase of temperature shows that the reaction is more spontaneous at a higher temperature. Therefore, it may be inferred that the ultimate adsorption mechanism of uranium-238 ions is intra-particle diffusion [21].

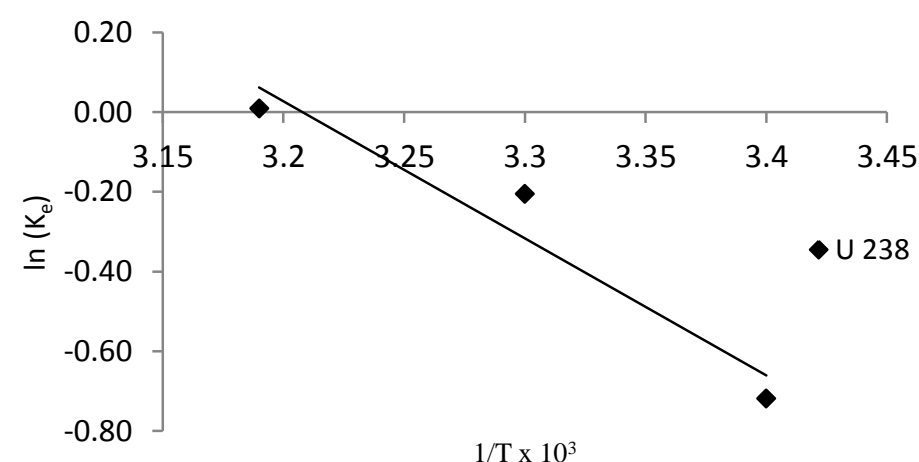

Fig. (11): The relationship between $\ln \left(K_{e}\right)$ and reciprocal of temperature, at a constant initial concentration of 
111.6 Bq/l, $1.0 \mathrm{~g} / \mathrm{l}$ dose of fly ash carbon and $600 \mathrm{rpm}$ for uranium-238

Table (1): Thermodynamic parameters of uranium-238ions onto fly ash carbon at a constant initial concentration of $111.6 \mathrm{~Bq} / 1$

\begin{tabular}{ccccc}
\hline & & \multicolumn{3}{c}{ Thermodynamic parameters } \\
\cline { 3 - 5 } Heavy metal & $\mathbf{T}$ & $\Delta \mathbf{G}^{\mathbf{0}}$ & $\Delta \mathbf{H}^{\mathbf{0}}$ & $\Delta \mathbf{S}^{\mathbf{0}}$ \\
& $(\mathrm{K})$ & $(\mathrm{kJ} / \mathrm{mol})$ & $(\mathrm{kJ} / \mathrm{mol})$ & $(\mathrm{J} / \mathrm{mol} . \mathrm{K})$
\end{tabular}

Uranium-238

$\begin{array}{llll}293 & -2620.424 & & \\ 303 & -4746.472 & -3.44 & 11.03 \\ 313 & -5502.611 & & \end{array}$

\subsection{Adsorption Kinetics}

Kinetics can be a means to understand the metal adsorption mechanisms and to evaluate the performance of the adsorbents for metal removal. To choose the optimum operating conditions for the full-scale batch process, the kinetics of uranium-238 adsorption on fly ash carbon is important which helps to predict the adsorption rate, provide valuable information to design and model the adsorption processes [22]. Laggren was thus used to adsorb uranium-238 on fly ash carbon in pseudo first order, pseudo-second - order kinetic models [23]. Uranium $^{238}$ removal by adsorption on fly ash carbon of contact time with different concentrations (27.9, 55.8 and 111.6 Bq/1) are shown in Figures (3, 4). Fly ash carbon exhibited a good adsorptive performance during the first $30 \mathrm{~min}$ [24]. A strong kinetic association is the explanation for the adsorption of metal ions during the solid phase. Figures.(14, 15) demonstrate the linear shape of the two ion sorption models at separate initial stages on fly ash material. Section 1.2 displays the theoretical conditions. Through comparing the $\mathrm{R}^{2}$ values, the validity of individual models is tested. As shown in Table (2), the uranium-238 adsorption in the resin is ideally suited for the second- pseudo order model. The pseudo second-order model is used for all concentrates, and the measured adsorption potential for balance is identical to the experimental results $\left(\mathrm{R}^{2}>0.998\right)$ large coefficients of correlation are reaches. For reversible reactions, with equilibrium between the liquid and solid phases [25], the first-order kinetic mechanism was used. The pseudo-secondary kinetic model on the other hand assumes that chemical adsorption may be the ratelimiting step. In this case, uranium-238 adsorption behavior requires the regulation of the intra-particle diffusion rate of adsorption [26].

\subsubsection{The pseudo-first-order kinetic model}

The pseudo-first - order model of Lagergren is the earliest known equation to define the adsorption rate based on adsorption capacity [26] :

$$
\ln \left(q_{e}-q_{t}\right)=\ln \left(q_{e}\right)-k_{1} t
$$

Where $\mathrm{q}_{\mathrm{e}}(\mathrm{mg} / \mathrm{g})$ and $\mathrm{qt}(\mathrm{mg} / \mathrm{g})$ are the values of the volume adsorbed per unit mass at equilibrium and at some time, $\mathrm{t}(\mathrm{min})$ is time, $\mathrm{k}_{1}\left(\mathrm{~min}^{-1}\right)$ is the pseudo-first order adsorption rate coefficient. The slope and intercept of a linear plot from $\ln \left(\mathrm{q}_{\mathrm{e}}-\mathrm{q}_{\mathrm{t}}\right)$ vs. $\mathrm{t}$ can be used to obtain values from $\mathrm{k}_{1}$ and $\mathrm{q}_{\mathrm{e}}$, listed in Figure $(16,17)$ and Table (2). To fit the experimental data into the equation, it is necessary to know the value of $\mathrm{q}_{\mathrm{e}}(8)$. A comparison of test values of the $\mathrm{q}_{\mathrm{e}}$ values and the values derived from the plots of $\ln \left(\mathrm{q}_{\mathrm{e}}-\mathrm{q}_{\mathrm{t}}\right)$ vs. $\mathrm{t}$ [28] is the basis for a real test on the validity of the equation. The correlation coefficients for the kinetic model are low and the difference of the adsorption capacity of equilibrium $\left(\mathrm{q}_{\mathrm{e}}\right)$ was observed between the experimental and the calculated data, indicating that the first-order adsorption of the experimental data is not suitable.

\subsubsection{The pseudo-second-order kinetic model}

Further analysis of the kinetic information with $\mathrm{H}_{\mathrm{o}}$ was carried out by Mackay [29] is assumed to be a pseudo-second - order adsorption. In linear form, the following can be written:

$$
\frac{t}{q_{t}}=\frac{1}{k_{2} q_{e}^{2}}+\frac{1}{q_{e}} t
$$

In $\mathrm{k}^{2}$, the pseudo second-order adsorption rate (mg $\left.\mathrm{g}^{-1} \min ^{-1}\right)$ is constant. The $\mathrm{t} / \mathrm{q}_{\mathrm{t}}$ relative to $\mathrm{t}$ Estimates. $(18,19)$ should be a linear equation from which the slope and intercept plot $\left(\mathrm{q}_{\mathrm{e}}=1 /\right.$ slope, $\mathrm{k}^{2}=(\text { slope })^{2} /$ intercept $)$ can be calculated. $(18,19)$.

A linear plot will analyze the implementation of the above two models which are seen in Figure (13). The $\mathrm{R}^{2}$ correlation coefficient from these plots was determined in order to measure the applicability of each model. Table (2) shows the kinetic rate constants from pseudokinetic first and second order simulations. For the pseudo-second - order adsorption model, the correlation coefficient $\mathrm{R}^{2}$ values are relatively high (>0.9979), and the measured adsorption potential of the model is very similar to those defined by experiments. However, $\mathrm{R}^{2}$ values are not sufficient in the pseudo-first order. The pseudo-secondary adsorption model was therefore more 
fitting to explain the kinetic adsorption of uranium-238 in fly ash carbon [30].

In general, the adsorption reaction is understood to take the following steps:

1. Moving of adsorbate from the bulk solution to the adsorbent surface, which is generally referred to as diffusion. Migration of adsorbate into pores.

2. Interaction of the adsorbate with accessible locations on the inside surface of the pores [31].

- The literature indicates that the rate-setting stage for the uranium-238 ion adsorption depends on the interaction of adsorbate with available sites on the interior surface of pores of the adsorbents.

- Uranium-238 ion transport through fly ash carbon pores [31].

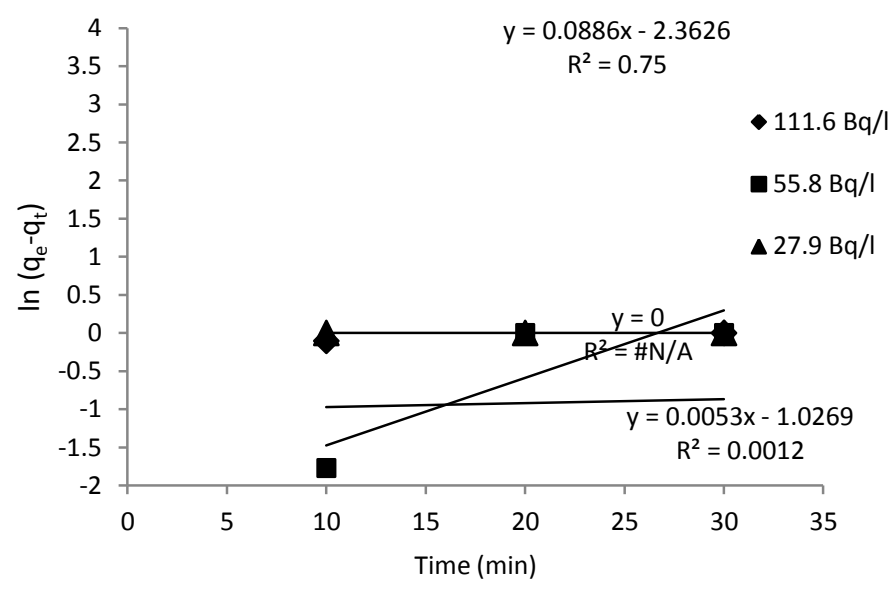

Fig. (12): Pseudo-first orders kinetic fit for the adsorption of uranium-238 metal ions onto fly ash carbon at different initial concentration, $1.0 \mathrm{~g}$ fly ash carbon dose, 600 rpm, and $303 \mathrm{~K}$.

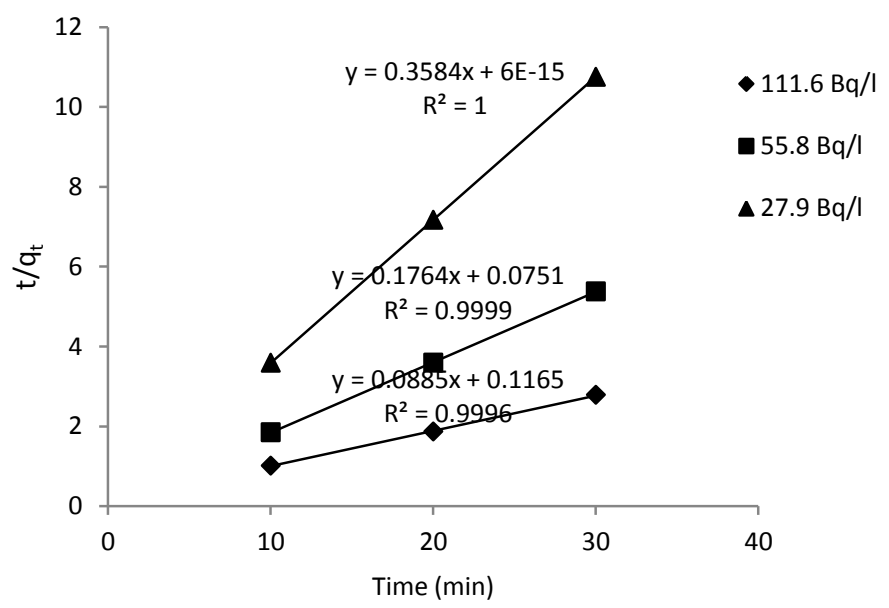

Fig. (13): Pseudo-second orders kinetic fit for the adsorption of uranium-238ion onto fly ash carbon at different initial concentration, $1.0 \mathrm{~g}$ fly ash carbon dose, $600 \mathrm{rpm}$, and $293 \mathrm{~K}$

\subsection{Equilibrium adsorption study}

It is important to explain how solutes interact with the sorbent adsorption isotherm. To plan and optimise adsorption processes, the creation of an effective isothermal model for adsorption is important. Several isothermic models for the evaluation of balance adsorption of compounds from solutions such as Langmuir, Freundlich, Redlich - Peterson, Dubinin Radushkevich, Sips, and Temkin have been developed [32]. Since Langmuir, Freundlich and Dubin Radushkevich equations are the most common models in the examination of the adsorption isotherm, the experimental results of these two models were matched. The adsorption of balanced isotherms is important for the determination of metal ions adsorbing capacity uranium -238 and for diagnosing the nature of the fly ash carbon [33].

\subsubsection{Langmuir model}

The theoretical Langmuir sorption isotherm [34] applies to the adsorption of a liquid solvent on a surface containing a limited number of identical sites. The solution is monolayer adsorption. The model is based on a few essential assumptions: 1. the sorption is performed at a specific, homogenous site inside the adsorbent; 2 . the site is occupied by uranium-238; 3) the adsorbent has a finite adsorbent capacity (equilibrium). Langmuir isotherm model assumes uniform energies of adsorption onto the surface without transmigration of adsorbate in the plane of the surface. Thus, for the estimation of the maximum adsorption capacity that corresponds to a full monolayer cover on the sorbent surface, the Langmuir isotherm model was chosen. In a linear shape, the Langmuir isotherm model is shown [34]

$$
\frac{\mathrm{C}_{\mathrm{e}}}{\mathrm{q}_{\mathrm{e}}}=\frac{1}{\mathrm{q}_{\max } \cdot \mathrm{b}}+\frac{\mathrm{C}_{\mathrm{e}}}{\mathrm{q}_{\max }}
$$

When $\mathrm{q}_{\mathrm{e}}$ is the adsorbent equilibrium metal ion concentration $(\mathrm{mg} / \mathrm{g}), \mathrm{q} \max$ is the adsorbent's monolayer adsorbent saturation power, while $b$ is a constant of Langmuir. Figure14 displays linear $\mathrm{C}_{\mathrm{e}} / \mathrm{q}_{\mathrm{e}}$ versus loops. It was used by means of a linear regression equation to determine the parameters of the Langmuir Isotherm. The value of the Langmuir constant was estimated and listed in Table (3) from this regression equation and linear map. The $b$ and $q$ max are reached respectively from the pitch and the detection of the plots. The exceptionally successful implementation of the 
Langmuir model to these adsorptions is shown by strong

$\mathrm{R}^{2}$ values for metal ions.

Table (2): Kinetic models and other parameters for adsorption of uranium-238 onto fly ash carbon at a different initial concentration of metal ions, $1.0 \mathrm{~g}$ dose, $600 \mathrm{rpm}, 293 \mathrm{k}$

\begin{tabular}{|c|c|c|c|c|}
\hline \multirow{2}{*}{ Kinetic models } & \multirow{2}{*}{ parameters } & \multicolumn{3}{|c|}{ Concentration of uranium-238 } \\
\hline & & $111.6(\mathrm{~Bq} / \mathrm{l})$ & $55.80(\mathrm{~Bq} / \mathrm{l})$ & $27.90(\mathrm{~Bq} / \mathrm{l})$ \\
\hline & $\mathrm{q}_{\mathrm{e}}(\operatorname{Exp})(\mathrm{mg} / \mathrm{g})$ & 10.79 & 5.58 & 2.79 \\
\hline $\begin{array}{c}\text { Pseudo-first order } \\
\text { equation }\end{array}$ & $\begin{array}{c}\mathrm{q}_{\mathrm{e}}(\text { calc. })(\mathrm{mg} / \mathrm{g}) \\
\mathrm{k}_{1}\left(\min ^{-1}\right) \\
\mathrm{R}^{2}\end{array}$ & $\begin{array}{l}1.0269 \\
0.0053 \\
0.0012\end{array}$ & $\begin{array}{c}-2.3626 \\
0.0886 \\
0.75\end{array}$ & $\begin{array}{l}0.0 \\
0.0 \\
0.0\end{array}$ \\
\hline $\begin{array}{l}\text { Pseudo-second order } \\
\text { equation }\end{array}$ & $\begin{array}{c}\mathrm{q}_{\mathrm{e}}(\text { calc. })(\mathrm{mg} / \mathrm{g}) \\
\mathrm{k}_{2}(\mathrm{~g} / \mathrm{mg} \cdot \mathrm{min}) \\
\mathrm{k}_{2} \mathrm{q}_{\mathrm{e}}^{2}(\mathrm{mg} / \mathrm{g} \cdot \mathrm{min}) \\
\mathrm{k}_{2} \mathrm{q}_{\mathrm{e}}^{2} \\
\mathrm{t}_{0.5} \\
\mathrm{R}^{2}\end{array}$ & $\begin{array}{c}11.299 \\
6.772\end{array}$ & $\begin{array}{c}5.668 \\
0.4143\end{array}$ & $\begin{array}{c}2.270 \\
2.14 * 10 \mathrm{E} 14\end{array}$ \\
\hline
\end{tabular}

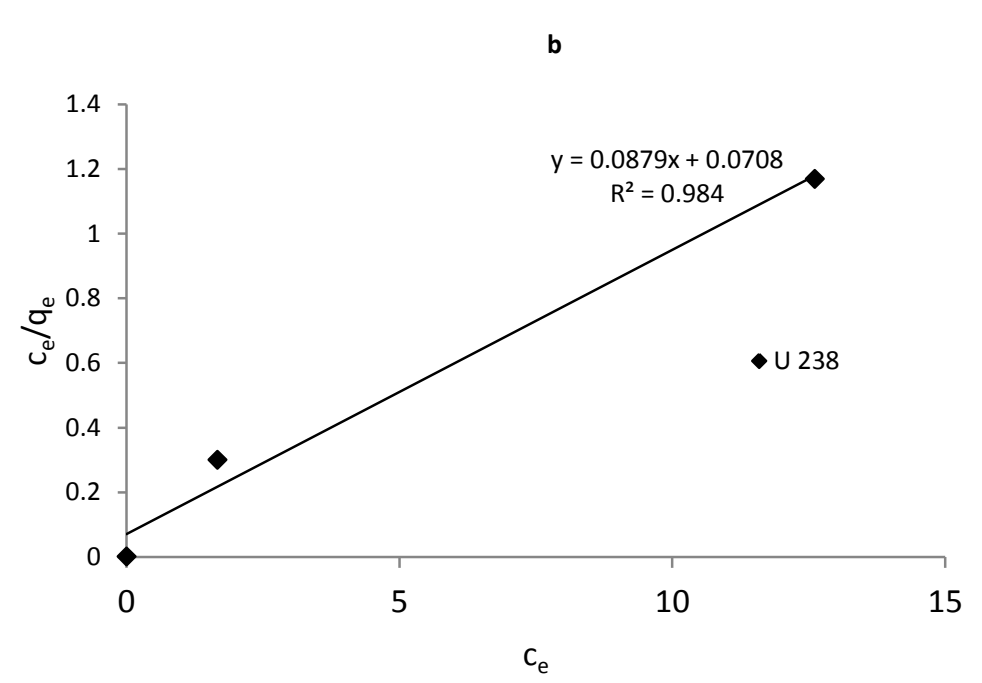

Fig. (14): The linear Langmuir adsorption isotherm for uranium-238 ions with fly ash carbon at $293 \mathrm{~K}$

In terms of a dimensionless constant separation factor $\left(R_{L}\right)$, the basic characteristics of the Langmuir isotherm can be expressed as:

$$
R_{L}=\frac{1}{1+b C_{o}}
$$

Where $\mathrm{C}_{\mathrm{o}}$ is the initial concentration of the metal ion. The values of $R_{L}$ indicate the type of isotherm to be either unfavorable $\left(R_{L}>1\right)$, linear $\left(R_{L}=1\right)$, favorable $(0$ $\left.<\mathrm{R}_{\mathrm{L}}<1\right)$ or irreversible $\left(\mathrm{R}_{\mathrm{L}}=0\right)$. From this study the $\mathrm{R}_{\mathrm{L}}$ values for uranium-238 ions adsorption ranged from 0.09 to 0.2 Therefore, the adsorption process is favorable [35].

\subsubsection{Freundlich model}

The Freundlich Isotherm Model defines the sorption mechanism as the oldest known interaction [36]. The model also indicates that as sorbent energy is finished in the sorption centers of an adsorbent, sorption energy decreases exponentially on heterogeneous surface with the interactions between adsorbed molecules and the application of the Freundlich equation. This isotherm is an analytical equation used to classify heterogeneous structures in the linear form.

$$
\log q_{e}=\log K_{f}+\frac{1}{n} \log C_{e}
$$

Where $\mathrm{K}_{\mathrm{F}}$ and 1 / $\mathrm{n}$ denote adsorption capability and strength respectively as the friendly constant. Figure(15) displays $\log \mathrm{q}_{\mathrm{e}}$ a linear plot against $\log \mathrm{C}_{\mathrm{e}}$ and slope and intercept constants $1 / \mathrm{n}$ and $\mathrm{K}_{\mathrm{F}}$ were respectively determined and listed in Table (3). The value of $1 / \mathrm{n}$, being less than 1 , indicates a strong adsorption and reinforcement of the adsorbent's heterogeneity. It also reveals that there is a close correlation between heavy metal ions and fly ash [37]. 
b

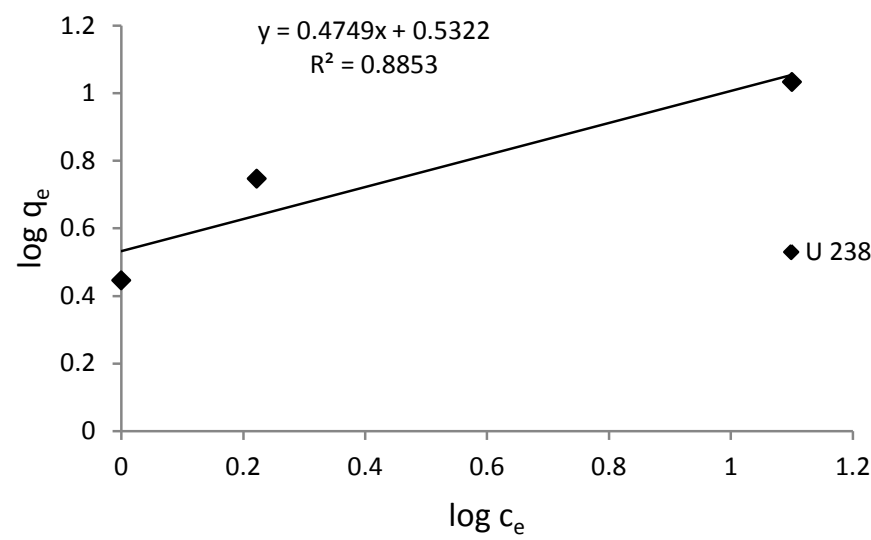

Fig. (15): The linear Freundlich adsorption isotherm for uranium-238 ions with fly ash carbon at $303 \mathrm{~K}$

\subsubsection{Dubinin-Radushkevich (D-R) isotherm model}

A semi-empirical equation, where adsorption follows a pore filling mechanism, is the $\mathrm{D}-\mathrm{R}$ Isotherm. It implies that the multi-layered adsorption is true with a Van der Waals power and for physical adsorption [38]. The linear shape of the $\mathrm{D}-\mathrm{R}$ model is as follows:

$$
\ln q_{e}=\ln q_{s}-K_{a d} \varepsilon^{2}
$$

Where $\mathrm{q}_{\mathrm{s}}$ is the theoretical isothermic saturation power $(\mathrm{mg} / \mathrm{g}), \mathrm{K}_{\mathrm{ad}}$ is the D-R isotherm constant $\left(\mathrm{mol}^{2} / \mathrm{J}^{2}\right)$ and $\pi$ is the Polanyi potential which is analogous to RT $\ln$ $\left(1+1 / \mathrm{C}_{\mathrm{e}}\right)$, where $\mathrm{R}(\mathrm{J} / \mathrm{mol})$.

Figure(16) shows a linear relation between $\ln \mathrm{q}_{\mathrm{e}}$ versus $\varepsilon^{2}$. The plot is divided into the $\mathrm{K}_{\mathrm{ad}}\left[\mathrm{mol}^{2} / \mathrm{J}^{2}\right]$ and the intercept provides the power of sorption $\mathrm{q}_{\mathrm{s}}$ alternate with (mg / g) [Table (3)]. The constant K Unexpected gives an idea of the mean free energy $\mathrm{E}(\mathrm{kJ} / \mathrm{mol})$ for adsorption per adsorbent molecule when it is transferred from infinity into the solution to the solid surface and can be calculated using the relation:

$$
\mathrm{E}=1 /\left(2 \mathrm{k}_{\mathrm{ad}}\right)^{1 / 2}
$$

It provides details on the mechanism for adsorption as the chemical ion exchange or actual adsorption. The magnitude of $\mathrm{E}$ ranges from 8 to $16 \mathrm{~kJ} / \mathrm{Mol}$, while the chemical ion-exchange adsorption process follows the physical nature of the adsorption process for values of $\mathrm{E}$ $<8 \mathrm{~kJ} / \mathrm{Mol}$. For uranium-238 the adsorption of the free average energy numerical value is $100 \mathrm{~kJ} / \mathrm{mol}$ leads to a physical process [39].

Finally, with the $\mathrm{R}^{2}$ values compared in Table (3), all the isothermic models are applicable.

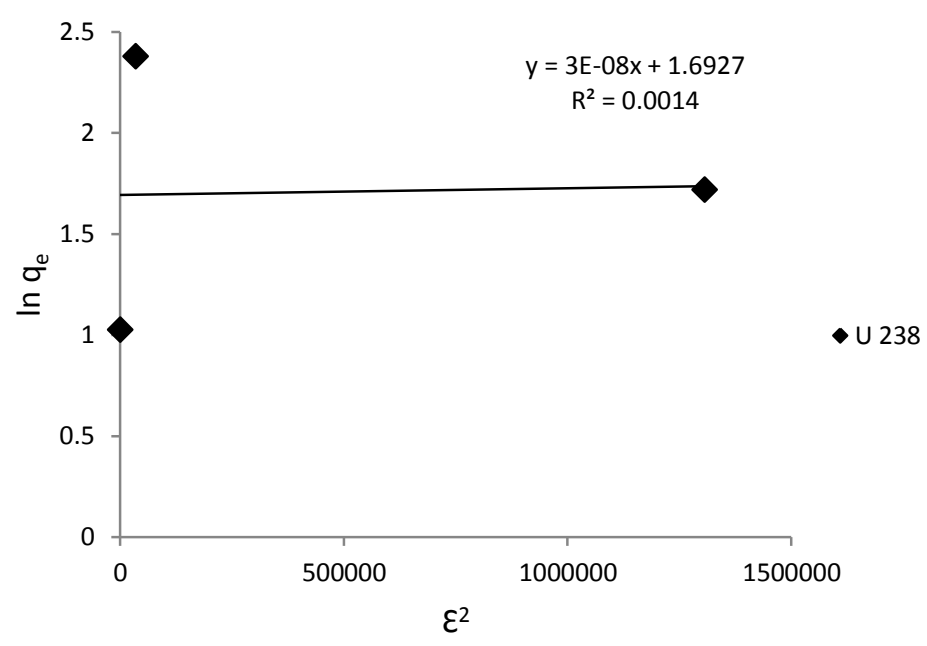

Fig. (16): The Dubinin-Radushkevich (D-R) adsorption isotherm for uranium-238 ions with fly ash carbon at $293 \mathrm{~K}$

\begin{tabular}{|c|c|c|c|c|c|c|c|c|c|c|c|}
\hline \multirow{3}{*}{$\begin{array}{c}\mathrm{C}_{\mathrm{o}} \\
(\mathrm{Bq} / \mathrm{l})\end{array}$} & \multicolumn{11}{|c|}{ Uranium-238 } \\
\hline & \multicolumn{3}{|c|}{ Langmuir } & \multicolumn{4}{|c|}{ Freundlish } & \multicolumn{3}{|c|}{ Dubinin-Radushkevich } & \multirow[b]{2}{*}{$\mathrm{R}^{2}$} \\
\hline & $\begin{array}{c}\mathrm{q}_{\max } \\
(\mathrm{mg} / \mathrm{g})\end{array}$ & $\stackrel{\mathrm{b}}{\left(\mathrm{dm}^{3} / \mathrm{mg}\right)}$ & $\mathrm{R}^{2}$ & $\mathrm{R}_{\mathrm{L}}$ & $1 / \mathrm{n}$ & $\mathrm{K}_{\mathrm{f}}$ & $\mathrm{R}^{2}$ & $\varepsilon$ & $\begin{array}{c}\mathrm{K}_{\mathrm{a}} \\
\mathrm{d}\end{array}$ & $\begin{array}{c}\mathrm{E} \\
(\mathrm{kJ} / \mathrm{mol})\end{array}$ & \\
\hline 111.6 & & & & 0.0925 & & & & 185.9 & & & \\
\hline 55.80 & 0.0708 & 0.0879 & 0.984 & 0.1693 & 0.4749 & 0.5322 & 0.8853 & 1143.1 & $2 \times 10^{-8}$ & 100 & 0.0049 \\
\hline 27.90 & & & & 0.2896 & & & & 0.0 & & & \\
\hline
\end{tabular}

Table (3): Adsorption isotherm constants for the adsorption of Uranium-238 onto fly ash carbon at $293 \mathrm{~K}$ 
$\mathbf{a}$

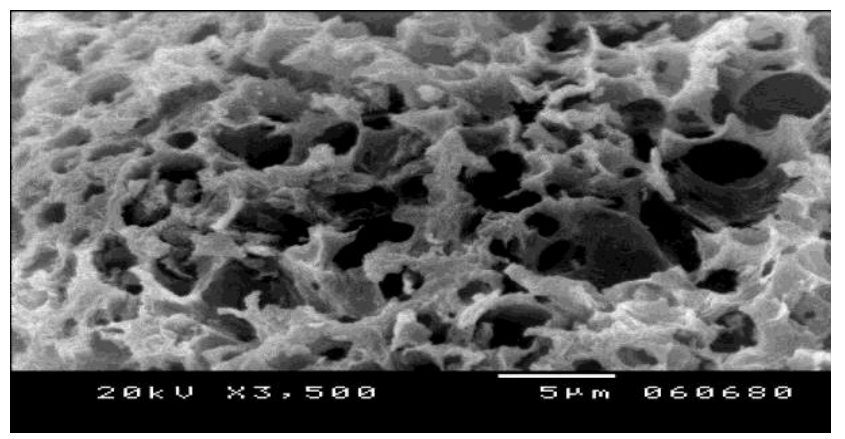

b

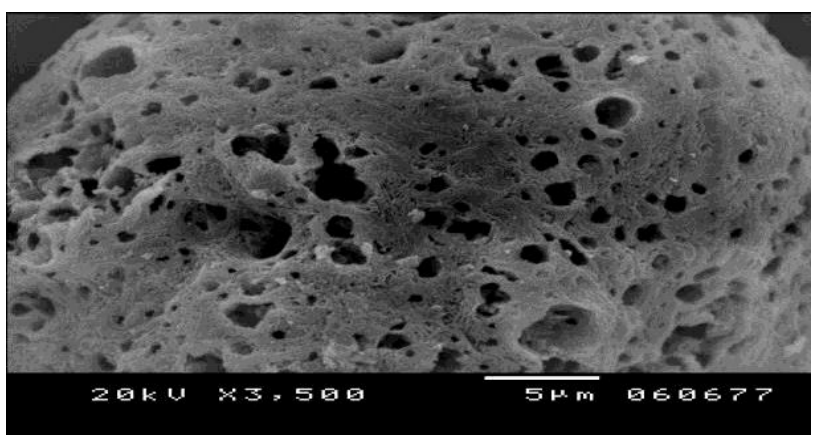

Fig. (17): The SEM micrographs indicated macropores in the fly ash carbon

\subsection{Scanning electron micrograph (SEM)}

SEM is widely used in the investigation of morphological properties of adsorbent materials and surface characteristics. A micrograph [40] shown in Figure (17) was provided with the morphological analysis of three types of fly ash carbon particles through electron microscopy scanning. SEM micrographs show that macropores contain large surfaces of carbon fly ash (Figure 17a) make for high performance heavy metals adsorbent. SEM is used in the present study to test morphologically transformed surfaces of fly ash carbon after uranium-238 ions have been adsorbed.

The SEM micrographs (Figure 17) of the fly ash carbon before and after the adsorption of uranium-238 ions with more curved lines, pores, and holes arrangement demonstrated distinct roughness. Figure $(17 \mathrm{~b})$ shows that major improvements have taken place in the surface morphology of fly ash carbon in the uranium-238ion adsorption. Figure (17 b) suggests that interlayer spaces which collapse, resulted in a tighter bonding structure, giving close-packed flakes.

\section{REFERENCE}

[1] Tuniz, Claudio, Richard Gillespie, and Cheryl Jones. The bone readers: science and politics in human origins research. Routledge, 2016.

[2] Meena, Ajay Kumar, et al. "Removal of heavy metal ions from aqueous solutions using carbon aerogel as an adsorbent." Journal of hazardous materials 122.1-2 (2005): 161-170.

[3] Rios, Carlos A., Craig D. Williams, and Clive L. Roberts. "Removal of heavy metals from acid mine drainage (AMD) using coal fly ash, natural clinker and synthetic zeolites." Journal of hazardous materials 156.1-3 (2008): 23-35.
[4] Xhixha, Gerti, et al. "The worldwide NORM production and a fully automated gamma-ray spectrometer for their characterization." Journal of Radioanalytical and Nuclear Chemistry 295.1 (2013): 445-457.

[5] Villaescusa, Isabel, et al. "Removal of copper and nickel ions from aqueous solutions by grape stalks wastes." Water research 38.4 (2004): 9921002.

[6] Rohlich, Gerard A. "Drinking Water and Health." Safe Drinking Water: Current and Future Problems (2016): 47-75.

[7] Owa, F. D. "Water pollution: Sources, effects, control and management." Mediterranean Journal of Social Sciences 4.8 (2013): 65.

[8] J. K. Edzwald, Water Quality and Treatment: A Handbook on Drinking Water, 6th ed, McGrawHill, (2011).

[9] Amal. Abdel- Hamid. Zaghlol, Gehan.Moustafa. El-Subruiti and Abdel Moneam. Ahmed Ibrahim "Kinetic study of cementation of copper on zinc metal in ethanol - water mixtures" Journal of Materials Science and Technology, 12 (1996): 41-45

[10] Xin, Xiaodong, et al. "Highly efficient removal of heavy metal ions by amine-functionalized mesoporous $\mathrm{Fe} 3 \mathrm{O} 4$ nanoparticles." Chemical Engineering Journal 184 (2012): 132-140.

[11] Prasad, Murari, and Sona Saxena. "Sorption mechanism of some divalent metal ions onto low-cost mineral adsorbent." Industrial \& engineering chemistry research 43.6 (2004): 1512-1522.

[12] Hubicki, Zbigniew, and Dorota Kołodyńska. "Selective removal of heavy metal ions from 
waters and waste waters using ion exchange methods." Ion Exchange Technologies (2012): 193-240.

[13] Dickhout, Janneke Marrit, et al. "Produced water treatment by membranes: a review from a colloidal perspective." Journal of colloid and interface science 487 (2017): 523-534.

[14] Chauhan, Garima, et al. "Novel technologies and conventional processes for recovery of metals from waste electrical and electronic equipment: challenges \& opportunities-a review." Journal of environmental chemical engineering 6.1 (2018): 1288-1304.

[15] Hubicki, Zbigniew, and Dorota Kołodyńska. "Selective removal of heavy metal ions from waters and waste waters using ion exchange methods." Ion Exchange Technologies (2012): 193-240.

[16] Dickhout, Janneke Marrit, et al. "Produced water treatment by membranes: a review from a colloidal perspective." Journal of colloid and interface science 487 (2017): 523-534.

[17] J. Wang and C. Chen, "Biosorbents for heavy metals removal and their future," Biotechnol. Adv., vol. 27, p. 195-226, (2009).

[18] Tuna, Aslı Özge Avc1, et al. "Removal of As (V) from aqueous solution by activated carbon-based hybrid adsorbents: Impact of experimental conditions." Chemical Engineering Journal 223 (2013): 116-128.

[19] Heintzelman, Brooks M. "The Day is Just Another Surface." (2019).

[20] Ekeocha, Christabel. "Uranium Mining and Milling in Nigeria." (2016).

[21] Schroeder, Terrence K. "Supercritical fluid enrichment of isotopes." U.S. Patent No. 7,967,893. 28 Jun. 2011.

[22] Gavrilescu, Maria, Lucian Vasile Pavel, and Igor Cretescu. "Characterization and remediation of soils contaminated with uranium." Journal of hazardous materials 163.2-3 (2009): 475-510.

[23] Sharifipour, F., et al. "Kinetics and thermodynamics of lead adsorption from aqueous solutions onto Iranian sepiolite and zeolite." International Journal of Environmental Research 9.3 (2015): 1001-1010.
[24] K. HardiljeetBoparai, M. Joseph, D. M. O'Carroll, Kinetics and thermodynamics of cadmium ion removal by adsorption onto nanozerovalent iron particles, J. Hazard. Mater.,vol.186, p.458(2011).

[25] F. Bouhamed , Z. Elouear and . J. Bouzid, "Adsorptive removal of copper(II) from aqueous solutions on activated carbon prepared from Tunisian date stones: Equilibrium, kinetics and thermodynamics," J. Taiwan Inst. Chem. Eng., In Press, (2012).

[26] Rudzinski, Wladyslaw, and Wojciech Plazinski. "Studies of the kinetics of solute adsorption at solid/solution interfaces: on the possibility of distinguishing between the diffusional and the surface reaction kinetic models by studying the pseudo-first-order kinetics." The Journal of Physical Chemistry C 111.41 (2007): 1510015110.

[27] Azizian, Saeid. "Kinetic models of sorption: a theoretical analysis." Journal of colloid and Interface Science 276.1 (2004): 47-52.

[28] Lin, Junxiong, and Lan Wang. "Comparison between linear and non-linear forms of pseudofirst-order and pseudo-second-order adsorption kinetic models for the removal of methylene blue by activated carbon." Frontiers of Environmental Science \& Engineering in China 3.3 (2009): 320324.

[29] Ho, Yuh-Shan, and Gordon McKay. "Pseudosecond order model for sorption processes." Process biochemistry 34.5 (1999): 451-465.

[30] Karkanas, Panagiotis I., and Ivana K. Partridge. "Cure modeling and monitoring of epoxy/amine resin systems. I. Cure kinetics modeling." Journal of applied polymer science 77.7 (2000): 1419-1431.

[31] Chowdhury, Pradip, Chaitanya Bikkina, and Sasidhar Gumma. "Gas adsorption properties of the chromium-based metal organic framework MIL-101." The Journal of Physical Chemistry C 113.16 (2009): 6616-6621.

[32] Foo, Keng Yuen, and Bassim H. Hameed. "Insights into the modeling of adsorption isotherm systems." Chemical engineering journal 156.1 (2010): 2-10.

[33] Afkhami, Abbas, Mohammad Saber-Tehrani, and Hasan Bagheri. "Simultaneous removal of 
heavy-metal ions in wastewater samples using nano-alumina modified with 2, 4dinitrophenylhydrazine." Journal of hazardous materials 181.1-3 (2010): 836-844.

[34] Singh, Harpreet, and Farzam Javadpour. "Langmuir slip-Langmuir sorption permeability model of shale." Fuel 164 (2016): 28-37.

[35] Wong, Y. C., et al. "Equilibrium studies for acid dye adsorption onto chitosan." Langmuir 19.19 (2003): 7888-7894.

[36] Ho, Yuh-Shan, Wen-Ta Chiu, and Chung-Chi Wang. "Regression analysis for the sorption isotherms of basic dyes on sugarcane dust." Bioresource technology 96.11 (2005): 12851291.

[37] Kumar, P. Senthil, et al. "Adsorption behavior of nickel (II) onto cashew nut shell: Equilibrium, thermodynamics, kinetics, mechanism and process design." Chemical Engineering Journal
167.1 (2011): 122-131.

[38] Nguyen, C., and D. D. Do. "The DubininRadushkevich equation and the underlying microscopic adsorption description." Carbon 39.9 (2001): 1327-1336.

[39] Boparai, Hardiljeet K., Meera Joseph, and Denis M. O'Carroll. "Kinetics and thermodynamics of cadmium ion removal by adsorption onto nano zerovalent iron particles." Journal of hazardous materials 186.1 (2011): 458-465.

[40] Batra, Vidya S., Sigita Urbonaite, and Gunnar Svensson. "Characterization of unburned carbon in bagasse fly ash." Fuel 87.13-14 (2008): 29722976. 